\title{
VIDA-DE-PRATELEIRA DE GOIABAS MINIMAMENTE PROCESSADAS ACONDICIONADAS EM EMBALAGENS SOB ATMOSFERA MODIFICADA ${ }^{1}$
}

\author{
Leila Mendes PEREIRA ${ }^{2}$, Alline Cristina Carpigiani RODRIGUES ${ }^{2}$, \\ Claire Isabel Grigoli de Luca SARANTÓPOULOS ${ }^{3}$, Valéria Christina Amstalden JUNQUEIRA4, \\ Helena Maria André Bolini CARDELLO ${ }^{5}$, Miriam Dupas HUBINGER ${ }^{2, *}$
}

\section{RESUMO}

Goiabas (Psidium guajava L.), variedade vermelha "Paluma", minimamente processadas por desidratação osmótica branda, foram acondicionadas em embalagens rigidas de polietileno tereftalato (PET) e estocadas à temperatura de $5^{\circ} \mathrm{C}$, com o objetivo de avaliar a influência da embalagem sob atmosfera modificada e do processo de desidratação osmótica na vida-de-prateleira do produto. Goiabas sem o tratamento osmótico, acondicionadas nas embalagens de PET e em ar atmosférico, foram utilizadas como controle. Durante a estocagem foram avaliadas a perda de peso, a contaminação microbiológica, as características físico-químicas do produto e as concentrações de $\mathrm{O}_{2}$ e $\mathrm{CO}_{2}$ no interior das embalagens. As goiabas foram submetidas também a uma análise sensorial de aceitação, acompanhada da avaliação da intenção de compra do produto pelo consumidor. Verificou-se que a combinação da temperatura de estocagem, da embalagem sob atmosfera modificada passiva e do processo de desidratação osmótica proporcionou às goiabas minimamente processadas uma vida-deprateleira de 24 dias, resultando num produto mais estável à contaminação microbiológica e com características sensoriais superiores às amostras controle, apresentando, também, melhor aceitação pelo consumidor.

Palavras-chave: goiaba; desidratação osmótica; processamento mínimo; embalagem sob atmosfera modificada.
\end{abstract}

\section{SUMMARY}

SHELF LIFE OF MINIMALLY PROCESSED GUAVAS STORED IN MODIFIED ATMOSPHERE PACKAGES. Guavas (Psidium guajava L.), var. "Paluma", minimally processed by mild osmotic dehydration, were packed in polyethylene terephthalate (PET) trays and stored at $5^{\circ} \mathrm{C}$, with the objective to evaluate the modified atmosphere package and osmotic dehydration influence on the shelf life of the product. Non-treated guavas, packed in PET trays and in atmospheric air, were used as control. Weight loss, microbial spoilage, physico-chemical characteristics of the product and oxygen and carbon dioxide concentrations inside the packages were evaluated during the shelf life of the product. The guavas were submitted to a sensory analysis and the purchase intention was also evaluated. The combination of storage temperature, passive modified atmosphere package and osmotic dehydration process provided a 24-day shelf life to the minimally processed guavas, resulting in a microbiologically more stable product with better sensory attributes than the control samples, also showing better acceptance by the consumer.

Keywords: guava; osmotic dehydration; minimal-processing; modified atmosphere packages.

\section{1 - INTRODUÇÃO}

A procura de produtos prontos para o consumo, com qualidade de frescos e contendo apenas ingredientes naturais tem crescido constantemente devido aos novos estilos de vida dos consumidores. Na Europa e nos Estados Unidos da América verifica-se um crescimento significativo da demanda desses produtos desde a década de 1990 [2]. O Brasil apresenta um crescimento de 10 a $15 \%$ ao ano dos produtos prontos para o uso, porém seu custo ainda é limitante para o aumento efetivo do consumo [15].

Devido a essa tendência, as frutas frescas têm aumentado sua popularidade em comparação às frutas processadas, porém a dificuldade de conservação e procura por praticidade levaram ao aparecimento das frutas minimamente processadas. O processamento minimo de frutas tem como objetivo fornecer um produto com caracte-

\footnotetext{
1. Recebido para publicação em 18/06/2002. Aceito para publicação em 26/06/2003 (000856).

2. Departamento de Engenharia de Alimentos, FEA - UNICAMP, CX. Postal 6121,CEP 13083-970, Campinas, SP, Brasil.mhub@fea.unicamp.br 3. Centro de Tecnologia de Embalagem, ITAL, CX. Postal 139, CEP 13073001, Campias, SP, Brasil.

4. Núcleo de Microbiologia, ITAL

Departamento de Planejamento Alimentar e Nutrição, FEA - UNICAMP. * A quem a correspondência deve ser enviada.
}

rísticas semelhantes as do produto fresco, sem perder suas qualidades nutricionais e com vida-de-prateleira suficiente para sua distribuição, comercialização e consumo, através da utilização de apenas processamentos brandos para assegurar sua qualidade.

As frutas minimamente processadas estão mais sujeitas à mudanças fisiológicas e bioquímicas e à deterioração microbiológica, que podem resultar na degradação da cor, textura e sabor, provocadas pelas operações de descascamento e corte [2, 13]. Faz-se necessária então, a utilização de uma combinação de processamentos brandos para assegurar a qualidade e aumentar a vidade-prateleira desses produtos.

A redução do conteúdo de umidade juntamente com o controle da atividade respiratória das frutas são fatores de extrema importância para garantir sua estabilidade e segurança, resultando no aumento da vida-deprateleira e na maior preservação dos atributos de qualidade.

A desidratação osmótica é um processo que proporciona a remoção parcial da água do alimento e resulta em um produto de alta qualidade, devido à possibilidade de impregnação de componentes de interesse sensorial e nutricional. O processo osmótico consiste em colocar pedaços de frutas ou hortaliças numa solução hipertônica de desidratação, sendo usualmente empregadas solu- 
ções de açúcares, causando uma saída de água do produto para a solução e uma transferência do soluto da solução desidratante para o produto. Porém a difusividade dos açúcares é usualmente menor que a da água, tornando possivel processos que resultam numa remoção substancial de água com apenas uma pequena absorção de açúcares [9].

A atmosfera modificada possibilita o estabelecimento de uma composição de gases ideal dentro da embalagem, onde a atividade respiratória do produto seja a menor possivel, prolongando sua vida-de-prateleira. O uso desse tipo de atmosfera, com o intuito de prolongar a vida-de-prateleira de produtos minimamente processados, sobretudo em frutas e hortaliças cortadas e lavadas, prontas para o consumo, tem sido abordado por KADER, ZAGORY \& KERBEL [8], GUNES \& LEE [5], HOWARD \& HERNANDEZ-BRENES [6].

Assim, o objetivo deste trabalho foi avaliar a influência da desidratação osmótica e da embalagem sob atmosfera modificada passiva associada à refrigeração, utilizando potes de polietileno tereftalato (PET) com tampa acoplada, na vida-de-prateleira de goiabas minimamente processadas, verificando também a aceitação desse produto pelo consumidor.

\section{2 - MATERIAL E MÉTODOS}

\section{1 - Material}

Foram utilizadas 60 goiabas (Psidium guajava L.) da variedade vermelha "Paluma", fornecidas pela Indústria Val Frutas (Vista Alegre do Alto, SP), selecionadas de acordo com tamanho, formato e grau de maturação maduro, definido pela coloração amarela da casca e teor de sólidos solúveis das frutas em torno de $7,2^{\circ} \mathrm{Brix}$.

Para o acondicionamento do produto utilizou-se embalagem rígida de polietileno tereftalato $(\mathrm{PET}) \mathrm{com}$ tampa acoplada, com capacidade de $350 \mathrm{~mL}$, marca Rotlen, da Treviplast (Avellaneda, Buenos Aires), com taxa de permeabilidade ao oxigênio de $430 \mathrm{~cm}^{3} / \mathrm{m}^{2} /$ dia e taxa de permeabilidade ao vapor d'água de $0,243 \mathrm{~cm}^{3} / \mathrm{m}^{2} /$ dia, e o filme de policloreto de vinila esticável (PVC) de $20 \mu \mathrm{m}$ da Goodyear (Americana, SP), com taxa de permeabilidade ao oxigênio de $8200 \mathrm{~cm}^{3} / \mathrm{m}^{2} /$ dia e taxa de permeabilidade ao vapor d'água de $262 \mathrm{~cm}^{3} / \mathrm{m}^{2} /$ dia, sendo o produto disposto em bandejas de poliestireno expandido, modelo M-52, da Meiwa (Arujá, SP).

\section{2 - Processo e estocagem}

As goiabas foram lavadas e sanitizadas com Desinfetante Clorado para verduras e frutas - Sumaveg, da Diversey Lever, na concentração de 0,55\% (p/v) durante 10 minutos, descascadas por tratamento químico, segundo ARGANDOÑA [3], lavadas em água corrente e imersas novamente na solução sanitizante a $0,55 \%(\mathrm{p} / \mathrm{v})$ por 10 minutos. Em seguida, foram cortadas em metades e as partes internas foram removidas, utilizando-se acessórios de aço inoxidável. As metades de goiaba foram colocadas em frascos, contendo a solução desidratante de sacarose comercial a $60^{\circ} \mathrm{Brix}$, previamente aquecida a $40^{\circ} \mathrm{C}$, na proporção fruta:solução de 1:10. Os frascos foram colocados em banho termostático, marca Tecnal, modelo TE-420, agitado a 120rpm, durante 2 horas [3]. Após o processo, as metades de goiaba foram enxaguadas com a solução sanitizante a $0,20 \%$ (p/v) e colocadas sobre papel absorvente para a remoção da solução em excesso. As goiabas osmoticamente desidratadas foram acondicionadas nas embalagens de PET, com o objetivo de promover uma modificação passiva da atmosfera ao redor do produto, sendo chamadas O.D. AM-PET. Foram utilizadas como controle goiabas in natura, descascadas e cortadas, acondicionadas nas embalagens de PET e nas bandejas de poliestireno expandido recobertas pelo filme de PVC esticável, sendo que este foi perfurado ( 7 furos de $0,7 \mathrm{~mm}$ de diâmetro) com o objetivo de manter as condições do ar atmosférico no interior da embalagem, estas amostras foram chamadas FRESCA AM-PET e FRESCA AR respectivamente. Todas as amostras foram estocadas à temperatura de $5^{\circ} \mathrm{C} d u-$ rante 24 dias.

\section{3 - Análises físico-químicas}

Todas as análises foram realizadas periodicamente, seguindo um mesmo intervalo de tempo $(0,5,10,14$, 18, 21 e 24 dias), e em triplicata. O pH das amostras foi determinado em pHmetro Sentron, modelo 2001 e a atividade de água com a utilização do equipamento Aqualab, modelo CX-2 (Decagon Devices Inc., Pullman,WA) à temperatura de $25^{\circ} \mathrm{C}$. A determinação da umidade das amostras foi feita utilizando estufa de convecção forçada a $60^{\circ} \mathrm{C}$, por 48 horas e a determinação de açúcares redutores e totais feita por método titulométrico, segundo a metodologia de Lane \& Eynon [14].

\section{4 - Análises microbiológicas}

As amostras foram examinadas quanto ao desenvolvimento de bolores e leveduras, coliformes, Salmonella e bactérias lácticas, segundo a metodologia proposta por VANDERZANT \& SPLITTSTOESSER [18], obedecendo a Resolução RCD no 12, de 2 janeiro de 2001, da AGÊNCIA NACIONAL DA VIGILÂNCIA SANITÁRIA [1].

\section{5 - Análise sensorial}

O produto foi submetido à análise sensorial de aceitação, utilizando-se escala hedônica não estruturada de $9 \mathrm{~cm}$, tendo como limites os termos "desgostei muitíssimo" à esquerda e "gostei muitíssimo" à direita, sendo avaliado em relação à aparência, cor, aroma, sabor, textura e impressão global por 30 provadores consumidores de goiaba. A intenção de compra do produto pelo consumidor também foi verificada. A análise sensorial foi realizada em duas etapas. Na primeira foram avaliados os atributos de aroma, sabor, textura, impressão global e intenção de compra, sendo as análises realizadas em cabines individuais, fornecendo-se um quarto de meia goiaba de cada amostra aos provadores, de forma monádica em pires brancos, codificados com números de 3 dígitos aleatórios. Na segunda etapa, avaliaram-se a aparência e a cor 
das amostras, sendo apresentadas aos provadores em blocos completos casualisados nas embalagens de acondicionamento, também codificadas com números de 3 dígitos aleatórios $[11,16]$.

\section{6 - Composição gasosa e perda de peso}

A determinação da composição gasosa no interior das embalagens foi realizada com a utilização do analisador de gases Dual Head Space Analyser, marca Mocon, modelo 650 e a perda de peso do produto durante a estocagem foi medida em balança semi-analítica marca Marte, modelo AM5500.

\section{7 - Análise estatística}

Os resultados foram avaliados estatisticamente através da Análise da Variância, aplicando o teste de Tukey ao nivel de $5 \%$ de significância, com o auxilio dos programas STATISTICA 5.0 e SAS, com o objetivo de verificar possiveis diferenças entre as amostras submetidas aos diferentes tratamentos e suas alterações durante a vida-de-prateleira.

\section{3 - RESULTADOS E DISCUSSÃO}

\section{1 - Caracterização da matéria-prima}

As Tabelas 1 e 2 apresentam, respectivamente, a composição química centesimal e a caracterização física da goiaba da variedade vermelha "Paluma" utilizada no experimento.

TABELA 1. Composição química centesimal da goiaba var. "Paluma".

\begin{tabular}{lc}
\hline \multicolumn{1}{c}{ Análise } & Valor Médio $(\%)$ \\
\hline Umidade (base úmida) & $87,26 \pm 0,48$ \\
Cinzas & $0,54 \pm 0,03$ \\
Proteínas & $1,42 \pm 0,06$ \\
Lipídeos & $0,31 \pm 0,05$ \\
Açúcares Totais & $2,80 \pm 0,31$ \\
Fibras & 6,91 \\
Acidez & $0,76 \pm 0,01$ \\
\hline
\end{tabular}

TABELA 2. Caracterização física da goiaba var. "Paluma".

\begin{tabular}{lc}
\hline \multicolumn{1}{c}{ Característica } & Especificação \\
\hline Peso Médio $(\mathrm{g})$ & $152,0 \pm 7,8$ \\
Diâmetro Médio $(\mathrm{cm})$ & $6,7 \pm 0,2$ \\
Comprimento Médio (cm) & $7,8 \pm 0,4$ \\
Espessura Média (cm) & $1,0 \pm 0,1$ \\
Sólidos Solúveis ( ${ }^{\circ}$ Brix) & $7,2 \pm 0,3$ \\
pH & $3,8 \pm 0,0$ \\
Atividade de Água & $0,991 \pm 0,002$ \\
\hline
\end{tabular}

\section{2 - Composição gasosa}

As embalagens de PET proporcionaram a modificação passiva da atmosfera ao redor do produto, atingindo teores em torno de 7,5\% de $\mathrm{O}_{2}$ e $18,5 \%$ de $\mathrm{CO}_{2}$ para as amostras osmoticamente desidratadas e 7,5\% de $\mathrm{O}_{2}$ e $16,5 \%$ de $\mathrm{CO}_{2}$ para as amostras frescas no final da estocagem. A utilização desse tipo de material de embalagem com o objetivo de modificar a composição gasosa da atmosfera de acondicionamento do produto também foi proposta por MATTIUZ et al. [10] e CARLOS et al. [4]. As condições do ar atmosférico ao redor do produto foram conseguidas com a utilização do filme de PVC esticável perfurado, utilizado na estocagem das amostras frescas.

\section{3 - Perda de peso}

As amostras acondicionadas sob atmosfera modificada passiva nas embalagens de PET (AM-PET), osmoticamente desidratadas (O.D.) e frescas, mostraram perda de peso relativamente pequena e constante durante os 24 dias de estocagem $(\mathrm{p}<0,05)$, indicando um equilibrio entre o ambiente da embalagem e o produto, porém a amostra fresca acondicionada sob as condições do ar atmosférico (FRESCA AR), utilizando o filme de PVC perfurado, apresentou aumento continuo de perda de peso, atingindo valores em torno de $11 \%$ no final da estocagem (Figura 1). Verificou-se então, que as embalagens rígidas de PET foram fundamentais para prevenir a perda de peso do produto, afirmando sua característica de barreira ao vapor d'água, conforme descrito por JENKINS \& HARRINGTON [7] e indicado pela baixa taxa de permeabilidade ao vapor d'água apresentada por essa embalagem.

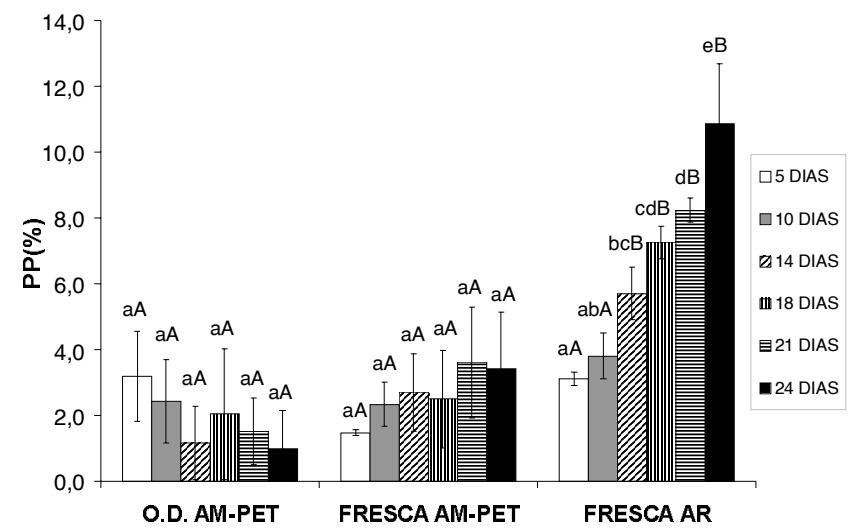

As letras minúsculas representam a variação de cada amostra com o tempo de estocagem e as letras maiúsculas representam a variação entre as amostras nos definidos tempos de estocagem. Colunas com a mesma letra minúscula ou maiúscula não diferem entre si para $\mathrm{p}<0,05$.

FIGURA 1. Perda de peso (PP) das goiabas durante a estocagem.

\section{4 - Contagem microbiológica}

Os resultados obtidos nas determinações de Salmonella e coliformes das amostras encontraram-se de acordo com os padrões microbiológicos estabelecidos pela Resolução RCD no 12, de 2 janeiro de 2001, da Agência Nacional da Vigilância Sanitária, apresentando ausência de Salmonella em $25 \mathrm{~g}$ de amostra e menos que 
10NMP/g de amostra de coliformes, indicando que a utilização das Boas Práticas de Fabricação e o processo de sanitização, a que foram submetidas as amostras, foram eficientes. Os beneficios dos cuidados higiênicos e dos processos de sanitização no processamento mínimo de frutas estão de acordo com TEIXEIRA et al. [17], que também não detectaram a presença de coliformes durante a estocagem dos mamões minimamente processados.

A amostra osmoticamente desidratada acondicionada sob atmosfera modificada passiva nas embalagens de PET apresentou maior estabilidade microbiológica que as amostras frescas sob atmosfera modificada passiva (PET) e em ar atmosférico, mostrando valores baixos $\left(\leq 1,0 \times 10^{2} \mathrm{UFC} / \mathrm{g}\right)$ e praticamente constantes de bolores e leveduras durante os 24 dias de estocagem e apenas um pequeno aumento de bactérias lácticas, atingindo o valor de 3,0x10UFC/g no final da estocagem, porém não prejudicial e imperceptivel sensorialmente.

As goiabas in natura acondicionadas sob atmosfera modificada passiva nas embalagens de PET apresentaram uma vida-útil bem reduzida devido ao desenvolvimento de aroma desagradável no 10 dia de estocagem, apresentando contagem de bactérias lácticas consideravelmente alta, em torno de $10^{2} \mathrm{UFC} / \mathrm{g}$, porém não mostrando contaminação significativa por bolores e leveduras durante todo o periodo. As goiabas in natura em ar atmosférico apresentaram uma maior vida-de-prateleira, comparativamente àquelas sob atmosfera modificada passiva em PET, porém mostraram presença de colônias de bolores e leveduras aos 21 dias, atingindo valores em torno de $10^{4} \mathrm{UFC} / \mathrm{g}$ no final da estocagem. Esse resultado mostra que as embalagens de PET não foram adequadas para o acondicionamento das goiabas frescas, podendo ter implicado na fermentação do produto devido às condições da atmosfera promovidas por esse tipo de embalagem.

A inibição do crescimento de bolores e leveduras promovida pela atmosfera modificada também foi verificada por MOHD-SOM et al. [12] em brócolis minimamente processados, mostrando que altos niveis de dióxido de carbono e baixos niveis de oxigênio apresentam efeitos benéficos na inibição desses microrganismos.

Com isso, pode-se concluir que o processo de desidratação osmótica juntamente com atmosfera modificada proporcionada pela embalagem de PET utilizada, com teores em torno de $7,5 \%$ de $\mathrm{O}_{2}$ e $18,5 \%$ de $\mathrm{CO}_{2}$, e a temperatura de estocagem de $5^{\circ} \mathrm{C}$ foram responsáveis por promover maior estabilidade microbiológica ao produto, quando comparado aos outros sistemas aqui avaliados.

\section{5 - Caracteristicas físico-químicas}

\subsection{1 - Açúcares redutores e totais}

Os teores de açúcares totais de todas as amostras, sendo que para as amostras frescas são iguais aos teores de açúcares redutores, pois estas não apresentaram açúcares não redutores em sua composição, permaneceram praticamente constantes ao longo da estocagem $(\mathrm{p}<0,05)($ Tabela 3). Observou-se também uma tendência ao aumento dos teores de açúcares redutores das amostras osmoticamente desidratadas (O.D.), podendo ser resultado da hidrólise da sacarose ocasionada pela acidez da fruta. As pequenas alterações ocorridas nos teores de açúcares totais das amostras durante o período de estocagem podem ser atribuídas à variabilidade da matéria-prima e não estão relacionadas com o tipo de embalagem e com o tempo de estocagem.

TABELA 3. Teores de açúcares das goiabas durante a estocagem.

\begin{tabular}{|c|c|c|c|c|c|c|c|}
\hline & & & TEMPO & (DIAS) & & & \\
\hline AMOSTRA & 0 & 5 & 10 & 14 & 18 & 21 & 24 \\
\hline $\begin{array}{l}\text { O.D. AM-PET } \\
\text { TOTAIS }\end{array}$ & $12,00^{\mathrm{aA}}$ & $13,40^{\mathrm{aA}}$ & $7,89^{\mathrm{bA}}$ & $11,27^{\mathrm{aA}}$ & $11,53^{\mathrm{aA}}$ & $13,02^{\mathrm{aA}}$ & $11,88^{\mathrm{aA}}$ \\
\hline $\begin{array}{l}\text { O.D. AM-PET } \\
\text { REDUTORES }\end{array}$ & $4,38^{a B}$ & $6,02^{a b B}$ & $5,12^{\mathrm{aB}}$ & $7,26^{\mathrm{bcB}}$ & $7,96^{\mathrm{bcB}}$ & $7,68^{\mathrm{bcB}}$ & $9,22^{\mathrm{cB}}$ \\
\hline $\begin{array}{l}\text { FRESCA AM-PET } \\
\text { RED/TOT. }\end{array}$ & $2,80^{a b C}$ & $2,87^{\mathrm{abC}}$ & $2,31^{a b C}$ & $2,10^{\mathrm{aC}}$ & $2,25^{\mathrm{aC}}$ & $3,43^{\mathrm{bc}}$ & $2,58^{\mathrm{abC}}$ \\
\hline $\begin{array}{l}\text { FRESCA AR } \\
\text { RED/TOT. }\end{array}$ & $2,80^{\mathrm{aC}}$ & $2,89^{\mathrm{aC}}$ & $2,68^{\mathrm{aC}}$ & $2,15^{\mathrm{aC}}$ & $2,20^{\mathrm{aC}}$ & $2,92^{\mathrm{aC}}$ & $2,47^{\mathrm{aC}}$ \\
\hline
\end{tabular}

Médias seguidas pela mesma letra minúscula na linha e maiúscula na coluna não diferem entre si para $\mathrm{p}<0,05$.

\subsection{2 - Umidade}

A umidade da amostra fresca sob atmosfera modificada passiva nas embalagens de PET (FRESCA AM-PET) permaneceu constante durante os 24 dias de estocagem $(\mathrm{p}<0,05)$, porém a amostra fresca em ar atmosférico (FRESCA AR) só apresentou esse comportamento após o 5o dia, mostrando uma redução em seu teor de umidade em relação ao início (Tabela 4). Esse comportamento também foi verificado para a amostra osmoticamente desidratada sob atmosfera modificada passiva em PET (O.D. AM-PET), que apresentou um decréscimo no teor de umidade no início e permaneceu constante no resto da estocagem. Isso mostra que as embalagens de PET evitaram a redução da umidade da amostra fresca no início da estocagem, porém não conseguiram manter constante o teor de umidade da amostra osmoticamente desidratada nesse mesmo periodo. Essa amostra continuou a perder água mesmo após sua retirada da solução desidratante, buscando o equilíbrio de umidade entre sua superficie e interior.

TABELA 4. Umidade em base úmida das goiabas durante a estocagem.

\begin{tabular}{|c|c|c|c|c|c|c|c|}
\hline & & & TEMPO & (DIAS) & & & \\
\hline AMOSTRA & 0 & 5 & 10 & 14 & 18 & 21 & 24 \\
\hline $\begin{array}{l}\text { O.D. } \\
\text { AM-PET }\end{array}$ & $78,57^{\mathrm{aA}}$ & $74,08^{\mathrm{bA}}$ & $74,44^{\mathrm{bA}}$ & $74,01^{\mathrm{bA}}$ & $72,49^{\mathrm{bA}}$ & $72,15^{\mathrm{bA}}$ & $73,45^{\mathrm{bA}}$ \\
\hline $\begin{array}{l}\text { FRESCA } \\
\text { AM-PET }\end{array}$ & $87,26^{a B}$ & $86,66^{a B}$ & $85,72^{\mathrm{aB}}$ & $87,10^{\mathrm{aB}}$ & $85,30^{\mathrm{aB}}$ & $84,79^{\mathrm{aB}}$ & $85,64^{a B}$ \\
\hline $\begin{array}{c}\text { FRESCA } \\
\text { AR }\end{array}$ & $87,26^{\mathrm{aB}}$ & $84,79^{\mathrm{bB}}$ & $84,34^{\mathrm{bB}}$ & $85,21^{\mathrm{abB}}$ & $84,31^{\mathrm{bB}}$ & $82,49^{\mathrm{bB}}$ & $85,03^{\mathrm{abB}}$ \\
\hline
\end{tabular}

\subsection{3 - Atividade de água}

Todas as amostras apresentaram o mesmo comportamento durante a estocagem em relação à atividade de água (Tabela 5), qual seja, uma pequena redução em seu valor após 10 dias, permanecendo constante até o 
final da estocagem $(\mathrm{p}<0,05)$. Esse comportamento mostra que só a partir do 10 dia as amostras entraram em equilibrio com o sistema de estocagem, ou seja, embalagem, temperatura e umidade relativa.

TABELA 5. Atividade de água das goiabas durante a estocagem.

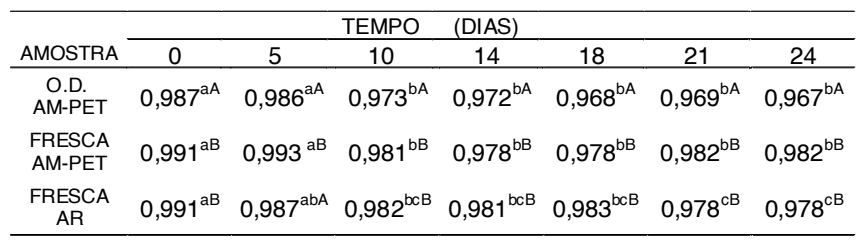

Médias seguidas pela mesma letra minúscula na linha e maiúscula na coluna não diferem entre si para $p<0,05$.

As diferenças verificadas durante a estocagem entre as amostras frescas e a amostra osmoticamente desidratada nos teores de açúcares e de umidade e nos valores de atividade de água são conseqüências do processo osmótico, que permite a redução do conteúdo de água das frutas, refletindo em sua umidade e atividade de água, juntamente com a incorporação dos açúcares presentes na solução desidratante.

\subsection{4 - pH}

A amostra osmoticamente desidratada e as amostras frescas tiveram seu $\mathrm{pH}$ praticamente constante durante todo o período da estocagem e não apresentaram diferença significativa entre seus valores em seus definidos tempos $(\mathrm{p}<0,05)$, como mostrado na Tabela 6. As pequenas variações apresentadas são provavelmente decorrentes da variabilidade da matéria-prima.

TABELA 6. pH das goiabas durante a estocagem.

\begin{tabular}{|c|c|c|c|c|c|c|c|}
\hline & & & TEMPO & (DIAS) & & & \\
\hline AMOSTRA & 0 & 5 & 10 & 14 & 18 & 21 & 24 \\
\hline $\begin{array}{l}\text { O.D. } \\
\text { AM-PET }\end{array}$ & $3,90^{\mathrm{abA}}$ & $3,76^{\mathrm{aAB}}$ & $3,95^{\mathrm{abA}}$ & $3,76^{\mathrm{aA}}$ & $3,86^{a b A}$ & $3,99^{\mathrm{bA}}$ & $3,94^{\mathrm{abA}}$ \\
\hline $\begin{array}{l}\text { FRESCA } \\
\text { AM-PET }\end{array}$ & $3,80^{\mathrm{aA}}$ & $4,06^{\mathrm{aA}}$ & $3,79^{\text {aA }}$ & $3,99^{\mathrm{aA}}$ & $3,98^{\mathrm{aA}}$ & $4,04^{\mathrm{aA}}$ & $3,92^{\mathrm{aA}}$ \\
\hline $\begin{array}{c}\text { FRESCA } \\
\text { AR }\end{array}$ & $3,80^{\mathrm{aA}}$ & $3,65^{a B}$ & $3,98^{\mathrm{aA}}$ & $3,88^{\mathrm{aA}}$ & $3,83^{\mathrm{aA}}$ & $3,94^{\mathrm{aA}}$ & $4,03^{\mathrm{aA}}$ \\
\hline
\end{tabular}

Médias seguidas pela mesma letra minúscula na linha e maiúscula na coluna não diferem entre si para $p<0,05$.

\section{6 - Análise sensorial}

\subsection{1 - Aceitação}

A análise sensorial das goiabas mostrou que as características de aroma, textura e aparência da amostra osmoticamente desidratada (O.D.) se apresentaram um pouco inferiores em relação à amostra in natura (FRESCA) antes da estocagem. O sabor, no entanto, se mostrou superior ao da amostra in natura e os outros atributos (impressão global e cor) permaneceram inalterados após o tratamento osmótico (Figura 2).

Com o acondicionamento das amostras osmoticamente desidratadas e frescas sob atmosfera modificada passiva nas embalagens de PET e da amostra fresca em ar atmosférico e com a estocagem à temperatura de $5^{\circ} \mathrm{C}$, as caracteristicas sensoriais da amostra osmoticamen- te desidratada foram se tornando superiores em relação às das amostras frescas. O desenvolvimento de aroma indesejável observado na amostra fresca acondicionada sob atmosfera modificada passiva nas embalagens de PET impediu sua avaliação sensorial após 10 dias de estocagem. Aos 18 dias (Figura 3), as características da amostra osmoticamente desidratada sob atmosfera modificada passiva em PET (O.D AM-PET), em geral, se mostraram significativamente superiores às da amostra fresca em ar atmosférico (FRESCA AR), sendo esta prejudicada principalmente nos atributos de sabor, aparência, cor e impressão global. Após 21 dias de estocagem verificou-se a presença de contaminação microbiana na amostra fresca acondicionada em ar atmosférico, tornando-a imprópria para o consumo. A amostra osmoticamente desidratada acondicionada sob atmosfera modificada passiva nas embalagens de PET, no entanto, continuou apresentando boas condições de consumo e grande aceitação pelo consumidor até o último dia de estocagem (24이), apresentando notas entre 6 e 7 para todos os atributos.

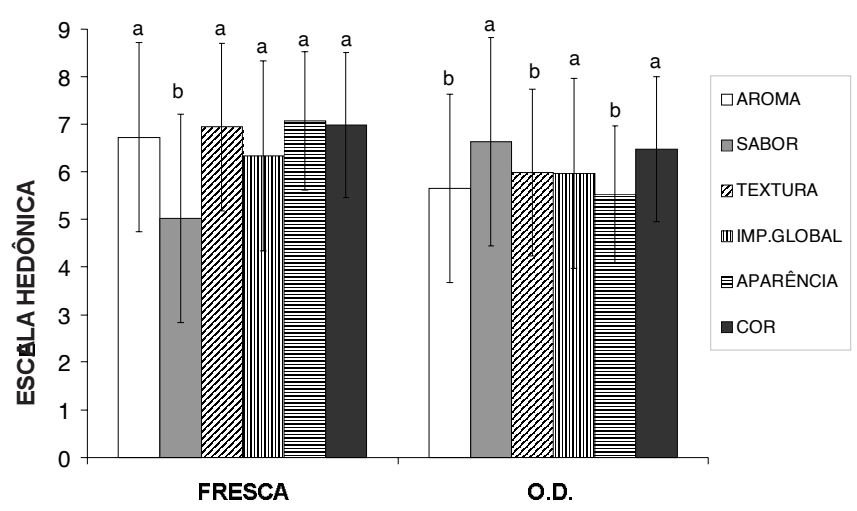

Colunas com a mesma letra não diferem entre si para $p<0,05$.

FIGURA 2. Análise sensorial das goiabas antes da estocagem.

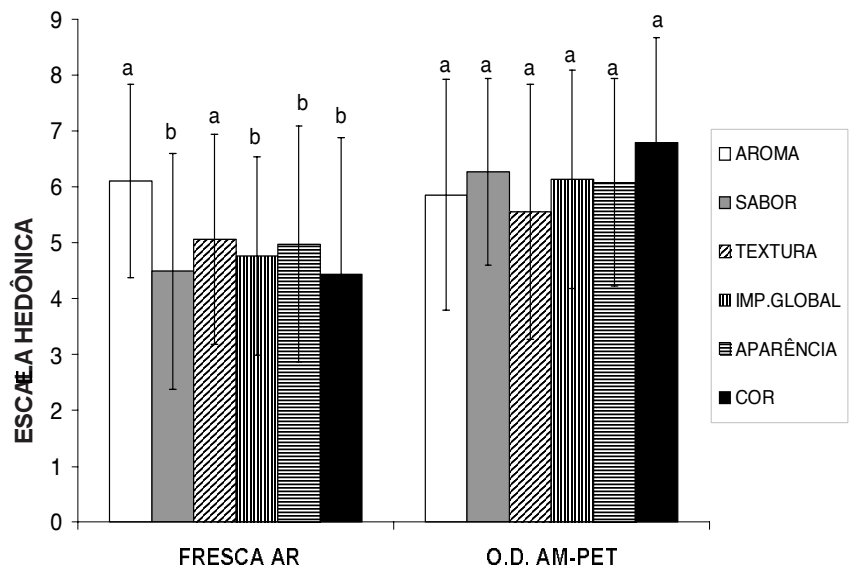

Colunas com a mesma letra não diferem entre si para $p<0,05$.

FIGURA 3. Análise sensorial das goiabas após 18 dias de estocagem.

A redução da aceitação dos provadores em relação a goiaba fresca acondicionada em ar atmosférico (FRESCA AR) está relacionada com o tempo de estocagem da amostra. Os percentuais de 90,41\%, 96,44\%, 90,78\% e $96,21 \%$ dessa redução da aceitação em relação à textu- 
ra, à impressão global, à aparência e à cor, respectivamente, podem ser explicados pelo aumento do tempo de estocagem do produto (Figura 4).

Para a amostra osmoticamente desidratada acondicionada sob atmosfera modificada passiva nas embalagens de PET (O.D. AM-PET) não houve correlação linear negativa significativa entre nenhum dos atributos sensoriais e o tempo de estocagem, mostrando que a estocagem não afetou as características de aroma, sabor, textura, impressão global, aparência e cor dessa amostra.

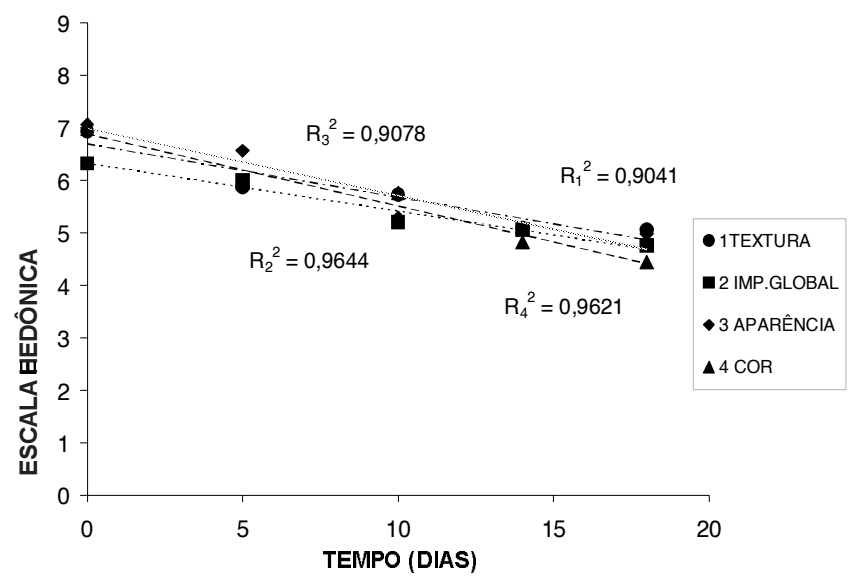

FIGURA 4. Influência do tempo de estocagem nos atributos sensoriais da goiaba fresca em ar atmosférico.

\subsection{2 - Intenção de compra}

Um comportamento praticamente constante e satisfatório (em torno de 60\%) em relação à intenção de compra do produto osmoticamente desidratado acondicionado sob atmosfera modificada passiva nas embalagens de PET (O.D. AM-PET) foi verificado durante todo o período de estocagem. A intenção de compra do consumidor em relação ao produto fresco em ar atmosférico (FRESCA AR), no entanto, mostrou uma redução ao longo da estocagem, chegando a cerca de $30 \%$ após 18 dias. Esses resultados são conseqüências das alterações dos atributos de aroma, sabor, textura, impressão global, aparência e cor verificadas durante a estocagem (Figura 5).

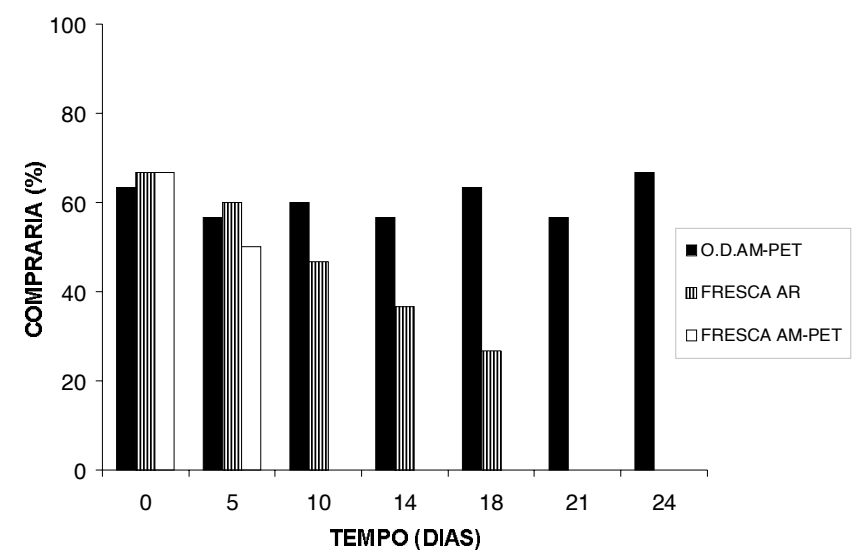

FIGURA 5. Intenção do consumidor em comprar as goiabas durante a estocagem.

\section{4 - CONCLUSÕES}

- Os resultados obtidos permitem concluir que as goiabas osmoticamente desidratadas acondicionadas sob atmosfera modificada nas embalagens de PET e estocadas à temperatura de $5^{\circ} \mathrm{C}$ apresentaram uma vida-de-prateleira de 24 dias, mantendo seus atributos sensoriais e características físico-quimicas praticamente constantes, indicando também que a combinação desses fatores resultou num produto mais estável à contaminação microbiológica e de melhor aceitação pelo consumidor, quando comparado aos controles, e de características similares à fruta fresca.

\section{5 - REFERÊNCIAS BIBLIOGRÁFICAS}

[1] AGÊNCIA NACIONAL DE VIGILÂNCIA SANITÁRIA. Resolução RCD n. 12, de 2 janeiro de 2001. http:// www.anvisa.gov. br. 2001.

[2] AHVENAINEN, R. New Approaches in Improving the Shelf Life of Minimally Processed Fruit and Vegetable. Trends in Food Science \& Technology, v. 7, p. 179-187, 1996.

[3] ARGANDOÑA, E. J. S. Desidratação de Goiaba por Imersão e Secagem. Campinas, 1999. 102p. Dissertação (Mestre em Engenharia de Alimentos) - Faculdade de Engenharia de Alimentos, Universidade Estadual de Campinas (UNICAMP).

[4] CARLOS, L.; COELHO, E. M.; CORDEIRO, C. A. M.; OLIVEIRA JÚNIOR, L. F. G.; ARAÚJO, T. M. Influência da Temperatura e do Período de Armazenamento nas Características Físico-Químicas, Sensoriais e Microbiológicas de Goiaba Minimamente Processada. II Encontro Nacional Sobre Processamento Mínimo de Frutas e Hortaliças, Viçosa,mg, 8-10 de novembro de 2000, p. 7.

[5] GUNES, G.; LEE, C. Y. Color of Minimally Processed Potatoes as Affected by Modified Atmosphere Packaging and Antibrowning Agents. Journal of Food Science, v. 62, p. 572-575, 582, 1997.

[6] HOWARD, L. R.; HERNANDEZ-BRENES, C. Antioxidant Content and Market Quality of Jalapeño Pepper Rings as Affected by Minimal Processing and Modified Atmosphere Packaging. Journal of Food Quality, v. 21, p. 317-327, 1998.

[7] JENKINS, W. A.; HARRINGTON, J. P. 1991. Packaging Foods with Plastics. Technomic Publishing Company, Lancaster.

[8] KADER, A. A.; ZAGORY, D.; KERBEL, E. L. Modified Atmosphere Packaging of Fruit and Vegetable. Critical Reviews in Food Science and Nutrition, v. 28, n. 1, p. 1-30, 1989 .

[9] KAREL, M. Osmotic Drying. In: Principles of Food Science. New York: Fennema, 1975. part II, p. 348-350.

[10] MATTIUZ, B.; DURIGAN, J. F.; TEIXEIRA, G. H. A., SARZI, B.; PINTO, S. A. A. Processamento Mínimo de Goiabas “ Pedro Sato". II Encontro Nacional Sobre Processamento Mínimo de Frutas e Hortaliças, Viçosa, MG, 8-10 de novembro de 2000 , p. 8.

[11] MEILGAARD, M.; CIVILLE, G.V.; CARR, B.T. 1988. Sensory Evaluation Techniques. CRC Press, Florida.

[12] MOHD-SOM, F.; KERBEL, E.; MARTIN, S. E.; SCHMIDT, S.J. Microflora Changes in Modified- AtmospherePackaged Broccoli Florets Stores at Refrigerated Temperature. Journal of Food Quality, v. 17, p. 347-360, 1994. 
[13] PARK, W. P. ; CHO, S. H.; LEE, D. S. Effect of Minimal Processing Operations on the Quality of Garlic, Green Onion, Soybean Sprouts and Watercress. Journal of Science of Food and Agriculture, v. 77, p. 282-286, 1998.

[14] RANGANNA, S. Manual of Analysis of Fruit and Vegetables Products. Central Food Technological Research Institute, Mysore, 1977.

[15] SAABOR, A. Informação pessoal - Frutas e Hortaliças: O Mercado Atual e o Fator Qualidade. Seminário Alimentos Minimamente Processados, Campinas, SP, 16-17 de outubro de 2000.

[16] STONE, H.; SIDEL, J.L. Sensory Evaluation on Practices. Academic Press, California, 1993.
[17] TEIXEIRA, G. H. A.; DURIGAN, J. F.; MATTIUZ, B.; ROSSI JÚNIOR, O. D. Processamento Mínimo de Mamão "Formosa". Ciênc. Tecnol. Aliment., v. 21, p. 47-50, 2001.

[18] VANDERZANT, C., SPLITTSTOESSER, D. F. 1992. Compendium of Methods for the Microbiological Examination of Foods. American Public Health Association, Washington.

\section{6 - AGRADECIMENTOS}

À Fundação de Amparo à Pesquisa do Estado de São Paulo - FAPESP, pelo apoio financeiro através da concessão de bolsa de Mestrado e ao CNPq (bolsa e projeto de apoio à pesquisa). 